\title{
CARE FOR HEALTH AMONG POLISH MEN, TAKING INTO ACCOUNT SOCIAL AND ECONOMIC FACTORS, AS WELL AS THE TYPE OF WORK
}

\author{
Katarzyna Hildt-Ciupińska, Karolina Pawłowska-Cyprysiak \\ Central Institute for Labour Protection - National Research Institute, Warsaw, Poland
}

\begin{abstract}
Background: Epidemiological studies show that an inappropriate healthy lifestyle is a major incidence factor, inter alia, for cardiovascular diseases, cancer, diabetes, obesity, as well as premature deaths, especially among men. Material and Methods: In order to check the attitudes of men towards health and health behaviors, a questionnaire-based research was carried out among 600 men active on the labor market. Several standard questionnaire tools were used: the Positive Health Behaviors Scale (PHBS), the List of Personal Values for measuring the place of health in the value hierarchy; the Multidimensional Health Locus of Control Scale, the Work Ability Index, the Psychological Sex Inventory, and the Work-Life Balance Subscale of the Copenhagen Psychosocial Questionnaire (COPSOQ II). Additionally, an independent questionnaire was developed. Results: In the PHBS, men could score 0-111 pts; the average score was $70.98 \mathrm{pts}$. A high level of care for health expressed in the scores ranging 80-111 pts was achieved by less than one-third of the respondents. One of the 4 groups (referred to as the "Active") achieved the best result according to PHBS, with an average score of 77 pts. The worst group (referred to as the "Frustrated") achieved an average of 54.5 pts. The latter performed physical or mixed work, and half of them worked shifts, including nights. Conclusions: The selected 4 groups were not found to differ from one another as much as the authors had expected, but they pointed to a very important aspect determining health care, namely socio-economic factors. There is a great need to conduct health education among men in Poland, targeted especially at young, low-educated and blue-collar workers. The areas of lifestyle that need to be changed are: nutrition, physical activity and preventive examinations. Med Pr. 2021;72(4):351-62
\end{abstract}

Key words: health, health behavior, men, type of work, care for health, socio-economic status

Corresponding author: Katarzyna Hildt-Ciupińska, Central Institute for Labor Protection - National Research Institute, Czerniakowska 16, 00-701 Warsaw, Poland, e-mail: kahil@ciop.pl

Received: August 21, 2020, accepted: February 24, 2021

\section{INTRODUCTION}

Men's health and well-being have become increasingly important in recent years in Europe - the European Region of the World Health Organization (WHO) [1]. A key factor triggering this attention is the high level of premature mortality among men, especially in the eastern part of the region. Life expectancy for men in the countries of the region in question ranged $62.2-81.3$ years in 2015 , while the average healthy life expectancy ranged 56.6-71.8 years. Although premature mortality rates are slowly improving in all countries, the differences between the East and the West have remained high. Similar differences also exist within countries and between groups of men with different socio-economic backgrounds. An increasing role among health determinants is attributed to gender in combination with other factors such as social, economic, cultural, environmental and health care [1]. Another important factor conditioning health and well-being, determined also by the above, is health care, expressed as a pro-health lifestyle manifested by pro-health behaviors (e.g., rational nutrition, physical activity).

Epidemiological studies indicate that inappropriate - or, in other words, unhealthy - lifestyle is the main factor of morbidity, inter alia, from cardiovascular diseases, cancer, diabetes and obesity, and also of premature death, especially among men [2]. The American research conducted already in the 1990s indicated that extensive lifestyle changes could cause even severe

Funding: this paper has been based on the results of a research project (No. I.N.07 entitled "Determinants of health-related behaviours and their effect on men's work ability," project manager: Katarzyna Hildt-Ciupińska, Ph.D.) carried out within the scope of the fourth stage of the National Programme "Improvement of safety and working conditions" partly supported in 2017-2019 - within the scope of research and development - by the Central Institute for Labour Protection - National Research Institute which is the Programme's main co-ordinator. 
coronary artery atherosclerosis to regress a year after the introduction of health behavior modifications to those more conducive to health [3]. Polish statistics show huge deficiencies in the area of knowledge and health education of men [4], which may be the main barrier in adopting a pro-health lifestyle by men.

Men are characterized, on the one hand, by good health self-assessment and failure to take advantage of medical services but, on the other hand, by excess mortality and more frequent, compared to women, behaviors unfavorable to health (e.g., excessive alcohol consumption, risky behaviors, extreme sports) $[4,5]$. Such trends as risky behaviors and an insufficient use of health services (e.g., not being screened) are observed among men in many countries, and are linked to socio-economic factors as well as to masculinity stereotypes [1].

Men's health, and especially individual care for it, is a topic rarely discussed in Poland. While there are statistics on morbidity, mortality and men's use of health care $[4,5]$, so far there have been few studies, especially qualitative, on male health care. The Siemens report [6] was, in the field of Polish research, innovative in this respect and brought new social threads (beliefs, attitudes and stereotypes) to the level of knowledge about men's health. However, there is still little information on how much, e.g., the type or place of work determine the health behaviors of men of different ages.

The results of these studies regarding health care and its determinants are presented in a paper titled "Positive health behaviors and their determinants among men active on the labor market in Poland" [7]. Both this and the aforementioned article present the results of research carried out with the same methods in a group of 600 men. In this paper, additional analyzes (including a cluster analysis) were presented, thanks to which it was possible to define 4 groups of men in terms of caring for health and other characteristics.

The aim of the paper is to characterize Polish men (defining groups of men) with regard to care for health and determining factors.

\section{MATERIAL AND METHODS}

The sample consisted of men $(\mathrm{N}=600)$ of working age (20-65 years), with different levels of education, including blue-, white- or mixed-collar workers, from several companies in Poland, who had agreed and wanted to participate in the research. The men represented several industries: shipbuilding, uniformed services, construction, as well as cleaning and security services.
The selection of the sample was deliberate and was made on the basis of age (20-65 years), gender (male) and type of work (physical, mental or mixed).

The method used was a survey, and the Positive Health Behaviors Scale (PHBS) was employed to measure health care [8]. Several standard questionnaire tools were used, including the List of Personal Values by Juczyński [9] for measuring the position of health in the value hierarchy; the Multidimensional Health Locus of Control Scale by Wallston, Wallston and DeVellis, in the Polish adaptation by Juczyński [9], the Work Ability Index by Tuomi et al. [10], the Psychological Sex Inventory [11], and the Work-Life Balance Subscale of the Copenhagen Psychosocial Questionnaire (COPSOQ II) [12].

Additionally, for the needs of the project, an independent questionnaire was developed, which included: a metric, including questions about height and body weight (to calculate the body mass index [BMI]) and questions concerning the self-assessment of health (from very good to very bad) and taking care of it (from "I care for it very much" to "I don't care for it at all"), motives for taking care of one's health, understanding the concept of "taking care of one's health" (an open-ended question) and sources of information about health (an open-ended question).

\section{Statistics}

In order to analyze the results of the research obtained from 600 males, the following studies were carried out.

\section{Cluster analysis}

In order to isolate groups of men with different styles of health care, a cluster analysis was carried out. A hierarchical cluster analysis was performed on the basis of standardized indicators of the PHBS and 3 questionnaire questions concerning physical activity, diet and smoking. It was decided to select 4 clusters (groups). Due to few data gaps, $98 \%$ of the respondents were assigned to groups.

\section{Significance of the differences}

The significance of the differences between the groups was determined using either fractional tests (if the response rates were compared) or t-tests for independent samples (if the means were compared). A fractional test is, in other words, a Z-test or a test of proportions between independent groups.

\section{Reliability}

The reliability of the PHBS and all its subscales was checked using Cronbach's a coefficient. The reliability of 
the whole scale was 0.933 , and for the subscale regarding nutrition, physical activity, maintenance of safety, sleep and mental health, as well as care for the body, Cronbach's a coefficients ranged 0.648-0.952.

\section{RESULTS}

\section{Characteristics of the examined men}

Most of the examined 600 men (38\%) were aged 3645 years; the second large group were people aged 27 35 years (34\%); the average age was 38.0 years. The mean $\mathrm{BMI}$ of the respondents was 27.5 , with the majority being overweight (52\%). The correct value of this indicator ranges $18.5-24.99$, and only $26 \%$ of men fell within that range (25-29 means overweight, 30-34.99 means first-degree obesity, and 35-40 means second-degree obesity).

Most of the respondents were in a relationship (83\%) and had children (70\%). The vast majority of men assessed their financial situation as average or good (70\%). Almost one-fourth had completed higher education, almost one-fifth held a bachelor's degree and one-fourth completed secondary vocational education. Most of them lived in cities/towns.

Most of the respondents (44\%) performed mixed work (mental and physical), and about $15 \%$ were employed in managerial positions. Shift work was performed by about $80 \%$, most of them in a continuous process industry, in the 8 -hour system (44.7\%).

Most of the surveyed men had a good ability to work (46.7\%). A vast majority (81\%) replied that they would be able to do their current job in about 2 years from now. Over $60 \%$ said they were satisfied with their daily activities; over $70 \%$ described themselves as active and lively, and over $65 \%$ were full of hope for the future. The detailed characteristics of the examined men is presented in Table 1.

The respondents assessed their health in a positive way - the majority (57\%) assessed their health and care for it as good. The vast majority (85\%) declared that they cared for their health, with health occupying a high position in their hierarchy of values (the majority of the respondents assigned a score of 4 or 5 on the scale of $1-5$, where 5 meant the most important value), and diseases were associated mainly with weakness, suffering, and pain. The men defined care for health as healthy eating, physical activity, avoiding all addictions and controlling their bodies (preventive examinations). More results are presented in the above-mentioned paper titled "Positive health behaviors and their determinants among men active on the labor market in Poland" [7].

\section{Care for one's health}

Care for one's health measured using the PHBS included 32 statements on pro-health behaviors related to: nutrition, body care, sleep/rest, maintaining safety, physical activity and avoiding anti-health behaviors related to smoking, excessive alcohol consumption, medication without consulting a doctor. In the whole scale, men could score 111 pts; the average score was 70.98 pts, and the minimum score was 8 pts. The obtained results were divided into 3 groups: low (0-62 pts), medium (63-79 pts) and high (80-111 pts). A high level of care for one's health was achieved by less than one-third of the respondents. Other average results for particular health behavior subscales and the model predicting determinants of care for one's health of the PHBS among Polish men, created using a multivariate linear regression analysis, are presented in the above-mentioned paper [7]

\section{Groups of men according to health care and other characteristics}

In order to isolate groups of men with different styles of health care, a cluster analysis was carried out. The selected 4 groups were not found to differ from one another as much as the authors had expected, but they pointed to a very important aspect determining health care, namely socio-economic factors. For the purposes of the paper, the groups were assigned the following symbols: A, B, C, D. Additionally, they were named according to the attributes that describe the men who were qualified to respective groups, i.e., A - "Family-oriented," B - "Friendly," C - "Active," and D - "Frustrated." The significance level was defined as $\mathrm{p}<0.05$ for some variables. Further details are presented in Table 2.

\section{The "Family-oriented" group}

As regards the PHBS (0 - 111 pts), the "Family-oriented" group achieved an average score of 70.1 pts (which for the whole group was 70.9). The "Family-oriented" group comprised slightly more people aged $>55$ years than the other groups. Half of this group members were overweight and 1 in 4 was obese. They were the second best educated group, after the "Active" group where almost half had higher education, every third was a white-collar worker and almost half had mixed jobs; they represented mainly 2 industries - uniformed services and construction.

Two-thirds of the "Family-oriented" group members rated their health as good or very good; four-fifths declared that they cared about their health, i.e., fewer than in the "Friendly" and "Active" groups, but more than in 
Table 1. Characteristics of the male sample (Jun 2017-June 2018, Poland)

\begin{tabular}{c} 
Variable \\
\multicolumn{2}{c}{$\begin{array}{c}\text { Participants } \\
(\mathrm{N}=600)\end{array}$} \\
\cline { 2 - 2 }
\end{tabular}

Age [years]

$<26$

$27-35$

$36-45$

46-55

$\geq 56$

BMI

underweight (16-18.49)

proper weight (18.5-24.99)

overweight (25-29.99)

obese $(\geq 30)$

Marital status

single

married

Place of residence

city

village

Educational level

elementary

junior high school

vocational

secondary

secondary vocational

post-secondary

bachelor's degree

master's degree

Type of work

mental

physical

mixed

Work system

shift work

including nights

excluding nights

non-shift work

other

Financial status

very bad

bad

average
444

156

54

204

228

66

48

0

156

312

498

102

83

17

74

26

0

6

90

72

150

30

108

144

162

174

264

44

$324 \quad 54$

Table 1. Characteristics of the male sample (Jun 2017-June 2018, Poland) - cont.

\begin{tabular}{cc} 
Variable & \multicolumn{2}{c}{$\begin{array}{c}\text { Participants } \\
(\mathrm{N}=600)\end{array}$} \\
\cline { 2 - 3 } & $\mathrm{n} \%$
\end{tabular}

Financial status - cont.

good

very good

$234 \quad 39$

Work ability

excellent

$168 \quad 28$

good

282

moderate

poor

$132 \quad 22$

Work ability prognosis for 2 years from now

unlikely

$12 \quad 2$

no certain

102

17

relatively certain

486

Have you recently been able to enjoy your regular daily activities?

$\begin{array}{lrr}\text { never } & 12 & 2 \\ \text { rather seldom } & 54 & 9 \\ \text { sometimes } & 168 & 28 \\ \text { rather often } & 228 & 38 \\ \text { often } & 144 & 24\end{array}$

Have you recently been active and alert?

never

rather seldom

61

sometimes

rather often

often

Have you recently felt full of hope for the future?

never

rather rarely

sometimes

$12-2$

42

7

rather often

144

24

continuously

252

$$
42
$$

Health self-assessment

150

25

very bad

bad

not good, not bad

good

very good

Care for health

yes, I care for my health

510

90

$6 \quad 1$

$12 \quad 2$

$144 \quad 24$

$342 \quad 57$

$96 \quad 16$

no, I don't care for my health
15 
the "Frustrated" group. They explained their negligence for health by referring to the lack of time and laziness, as well as to their financial situation. Every third person declared physical activity and healthy eating (again fewer than in the "Friendly" and "Active" groups, but more than in the "Frustrated" group). Almost none of the members smoked and they relatively rarely drank strong alcohol (vodka), which makes this group similar to the "Active" group.

In the context of the PHBS, the "Family-oriented" group, just like the "Active" group, distinguished themselves by a high score on the subscale of not taking risky behaviors, and just like the "Frustrated" group, by a low score on the scale of physical activity.

They reported ailments such as back pain, headaches, fatigue or anxiety slightly more often than the "Friendly" group. More than half of them declared that they were happy with everyday activities, and also that they were active and lively.

Three-fifths of the "Family-oriented" group members declared that being needed by other people is an important value for them; it was the highest rate of all groups. Like the "Friendly" group, half of them described themselves as sensitive. They more often spoke of themselves as being involved in the affairs of others, credible, economical, but not arrogant and not success-oriented as the other groups did. They cared less about their health but also harmed their health less, and worked in various industries - often in the uniformed services and construction industry (Tables 2 and 3 ).

\section{The "Friendly" group}

As regards the PHBS (0-111 pts), the "Friendly" group achieved an average score of 75.7 pts (which for the whole group was 70.9). That group was similar in many aspects to the "Family-oriented" group, but its members were distinguished, above all, by greater care for their health, similar to the "Active" group. They stood out in plus on the subscales regarding nutrition, care for the body, sleep and rest, but in minus on the subscale regarding avoiding risky behaviors.

They rated their health highly $-82 \%$ indicated that it was good or very good (more than in the "Frustrated" and "Family-oriented" groups). Moreover, 98\% of them, which is more than in the case of the "Frustrated" and "Family-oriented" groups, said they cared about their health because it was a value, because they were the breadwinners of their family, and because that way they would avoid diseases. As many as $92 \%$ declared that they were physically active, which is more than in the 2 groups mentioned above. Nearly half of them smoked cigarettes and drank vodka slightly more frequently than members of the "Active" and "Familyoriented" groups (but less frequently than members of the "Frustrated" group). They declared limiting risky behaviors, such as drinking, smoking (including passive smoking) or disregarding doctor's recommendations less frequently than members of the "Active" and "Family-oriented" groups did.

As much as $62 \%$ of the "Friendly" group members - similar to the "Active" group, and more than in the "Frustrated" and "Family-oriented" groups - rated their health as better than that of other people of their age. They were most satisfied with their lives (94\%), and derived personal happiness from health (90\%) and a large circle of friends (60\%). They most frequently of all indicated that a nice look was important for them (16\%). Most of all, every fourth member spoke of themselves as "coquettish." They trusted doctors more often than members of the "Frustrated" and "Family-oriented" groups. They rated satisfaction with daily tasks, activity and liveliness, and hope for the future, as high as the "Active" group but higher than the "Frustrated" and "Family-oriented" groups. They worked in the shipbuilding industry more often than the other respondent groups (Tables 2 and 3).

\section{The "Active" group}

As regards the PHBS (0-111 pts), the "Active" group achieved an average score of $77 \mathrm{pts}$ (which for the whole group was 70.9). The "Active" group members were relatively the youngest and included many representatives of uniformed services. They achieved the highest scores of all the groups on the subscale regarding physical activity, and they avoided dangerous behaviors to the highest extent, just like the "Family-oriented" group. In the caring for the body and maintaining safety, they exceeded the "Frustrated" group. They were best educated of all groups (with $>50 \%$ of its members having higher education), and more than half of them performed a mixed type of work.

In the context of their own health and diet assessment, they were similar to the "Friendly" group and scored higher than the "Family-oriented" and "Frustrated" groups. As many as $85 \%$ rated their health as good or very good, and the same percentage assessed their nutrition as good. Almost no one smoked there, and they consumed significantly less alcohol. Both in terms of avoiding risky behaviors and in terms of compliance with medical recommendations, they were 
Table 2. Characteristics of various men's groups (June 2017-June 2018, Poland)

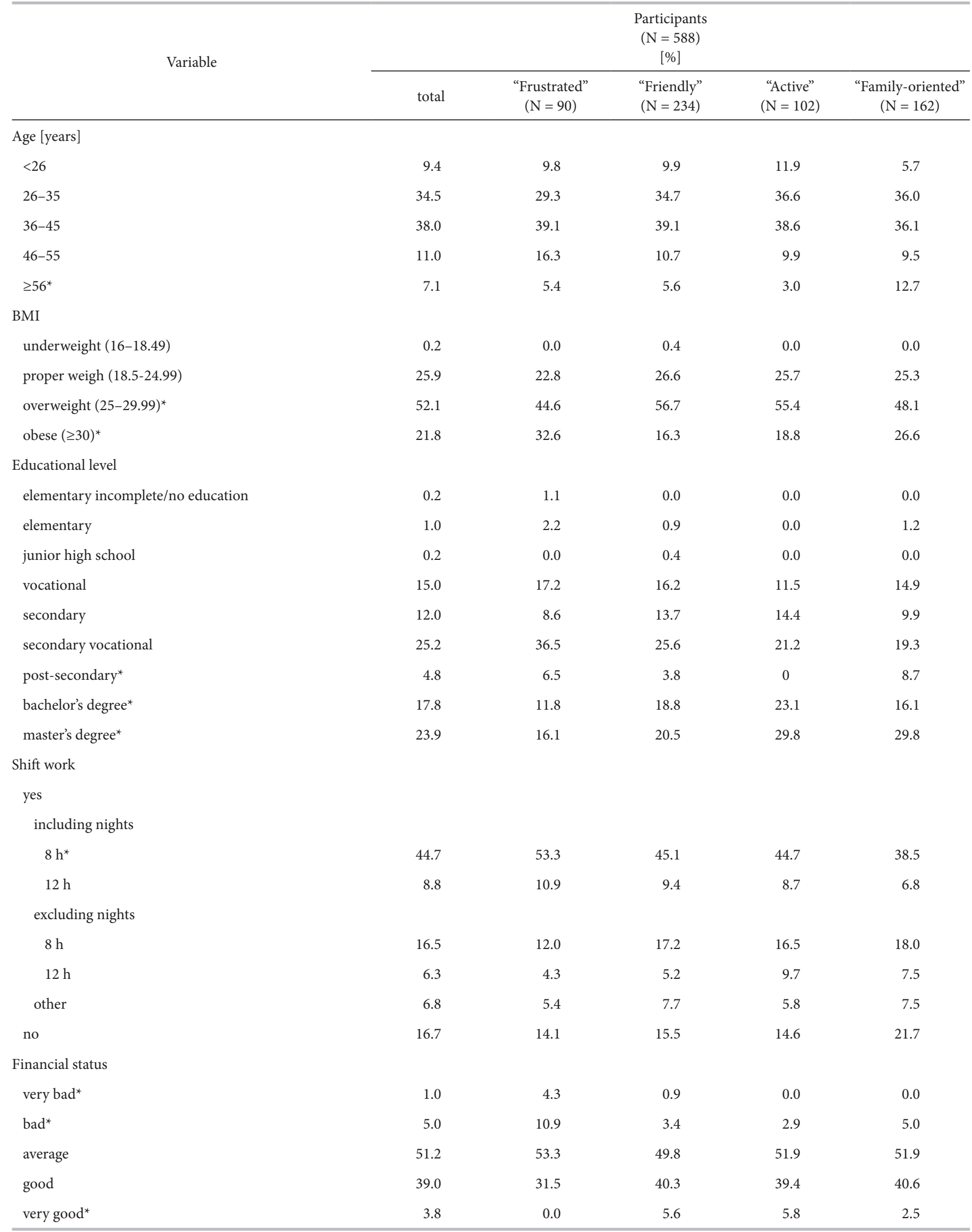


Table 2. Characteristics of various men's groups (June 2017-June 2018, Poland) - cont.

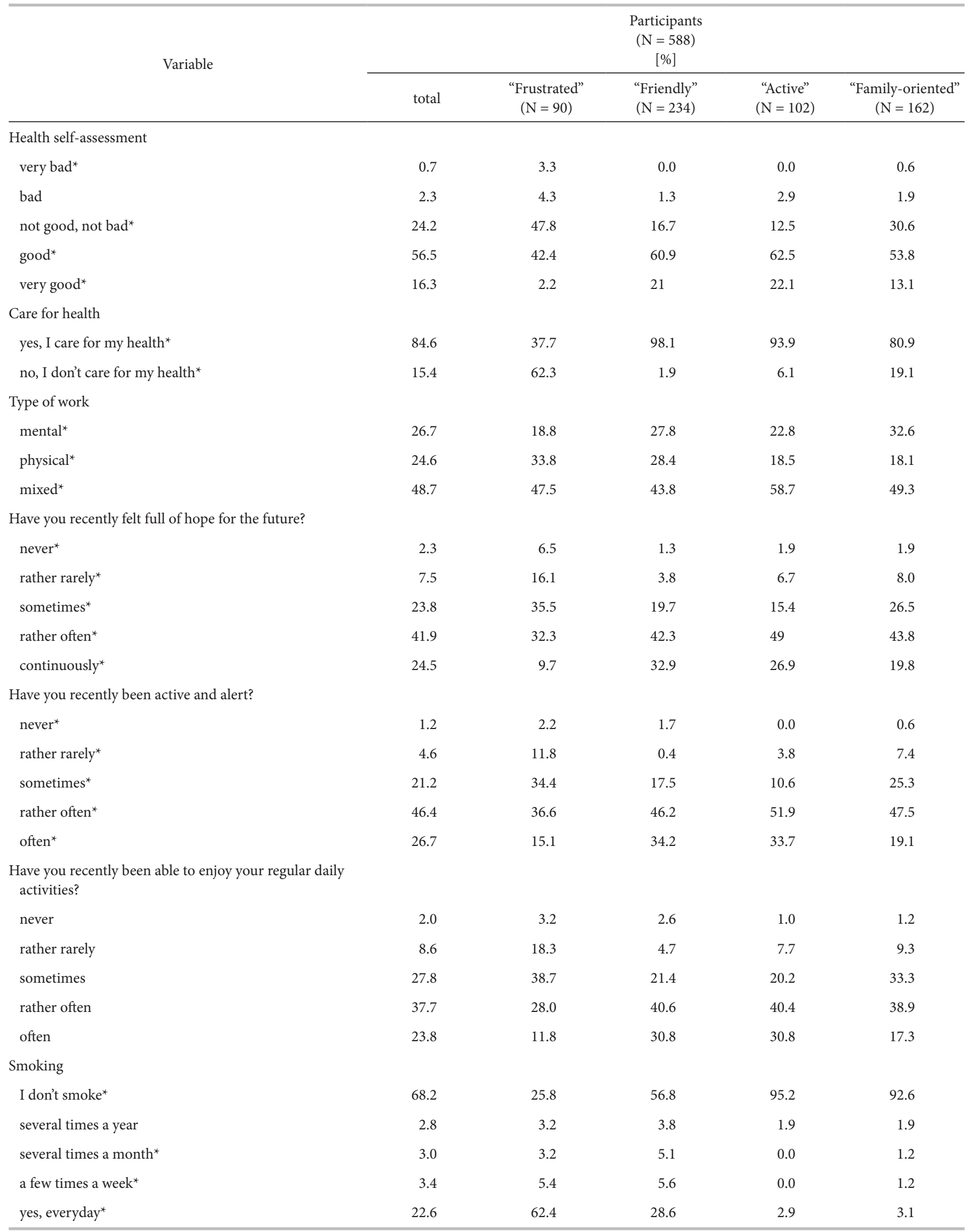


Table 2. Characteristics of various men's groups (June 2017-June 2018, Poland) - cont.

\begin{tabular}{|c|c|c|c|c|c|c|}
\hline & \multirow[t]{2}{*}{ Variable } & \multicolumn{5}{|c|}{$\begin{array}{c}\text { Participants } \\
(\mathrm{N}=588) \\
{[\%]}\end{array}$} \\
\hline & & total & $\begin{array}{l}\text { "Frustrated" } \\
(\mathrm{N}=90)\end{array}$ & $\begin{array}{l}\text { "Friendly" } \\
(\mathrm{N}=234)\end{array}$ & $\begin{array}{l}\text { "Active" } \\
(\mathrm{N}=102)\end{array}$ & $\begin{array}{c}\text { "Family-oriented" } \\
\quad(\mathrm{N}=162)\end{array}$ \\
\hline \multicolumn{7}{|c|}{ Alcohol consumption } \\
\hline never & & 5.8 & 7.0 & 5.8 & 6.3 & 5.2 \\
\hline rarely $^{*}$ & & 34.0 & 10.5 & 34.8 & 35.4 & 44.2 \\
\hline every month* & & 22.5 & 20.9 & 25.9 & 28.1 & 16.2 \\
\hline every week ${ }^{*}$ & & 30.8 & 43 & 28.6 & 30.2 & 27.3 \\
\hline daily* & & 6.9 & 18.6 & 4.9 & 0 & 7.1 \\
\hline
\end{tabular}

${ }^{*} \mathrm{p}<0.05$.

Table 3. The Positive Health Behavior Scale (PHBS) of men (June 2017-June 2018, Poland)

\begin{tabular}{|c|c|c|c|c|c|}
\hline \multirow[t]{2}{*}{ PHBS subscale } & \multicolumn{5}{|c|}{$\begin{array}{c}\text { Participants } \\
(\mathrm{N}=600) \\
{[\mathrm{pts}]} \\
(\mathrm{M} \pm \mathrm{SD})\end{array}$} \\
\hline & total & $\begin{array}{l}\text { "Frustrated" } \\
(\mathrm{N}=90)\end{array}$ & $\begin{array}{l}\text { "Friendly" } \\
(\mathrm{N}=234)\end{array}$ & $\begin{array}{l}\text { "Active" } \\
(\mathrm{N}=102)\end{array}$ & $\begin{array}{c}\text { "Family-oriented" } \\
(\mathrm{N}=162)\end{array}$ \\
\hline Nutrition $^{*}$ & $14.65 \pm 5.00$ & $10.82 \pm 4.76$ & $17.0 \pm 4.65$ & $13.89 \pm 4.01$ & $13.97 \pm 4.52$ \\
\hline Care for one's body* & $14.99 \pm 3.91$ & $12.38 \pm 4.25$ & $16.2 \pm 3.34$ & $15.50 \pm 3.07$ & $14.59 \pm 4.14$ \\
\hline Sleep, relax, mental health ${ }^{*}$ & $13.37 \pm 3.97$ & $11.24 \pm 3.64$ & $15.1 \pm 3.64$ & $13.18 \pm 3.86$ & $12.19 \pm 3.63$ \\
\hline Safe behaviors ${ }^{\star}$ & $11.61 \pm 2.60$ & $10.85 \pm 2.51$ & $11.69 \pm 2.62$ & $12.5 \pm 1.83$ & $11.42 \pm 2.90$ \\
\hline Physical activity* & $6.43 \pm 2.85$ & $4.2 \pm 2.29$ & $7.3 \pm 2.35$ & $9.0 \pm 2.28$ & $4.7 \pm 2.11$ \\
\hline Not engaging in risky behavior* & $10.66 \pm 4.01$ & $6.4 \pm 2.64$ & $8.91 \pm 3.62$ & $13.4 \pm 2.43$ & $13.6 \pm 2.04$ \\
\hline Total & $70.98 \pm 16.38$ & $54.48 \pm 14.28$ & $75.68 \pm 15.11$ & $76.98 \pm 14.00$ & $70.14 \pm 14.11$ \\
\hline
\end{tabular}

${ }^{*} \mathrm{p}<0.05$.

similar to the "Family-oriented" group. They slightly more often than the other groups felt that their private lives had a negative impact on their work. Apart from health, a life full of adventures was an important value for them. They assessed their health as better than that of other people of their age $(>60 \%)$. They trusted doctors and believed that by following medical recommendations they would maintain good health. They saw themselves as independent, responsible, competitive, success-oriented, caring for their appearance, self-confident, and friendly. They rated their physical condition higher than the other groups of respondents. Finally, they enjoyed their daily activities, hope for the future, as well as felt most active and lively (Tables 2 and 3 ).

\section{The "Frustrated" group}

As regards the PHBS (0-111 pts), the "Frustrated" group achieved an average score of 54.5 pts (which for the whole group was 70.9); it was the lowest result in comparison to all the groups. Although this was the smallest group, it was the one that attracts considerable attention, because it stands out the most in a negative way, especially given the results of the PHBS, where they scored the lowest among all the groups of men. In this group, one could most often meet employees of companies hiring security guards and cleaning staff. They did not stand out in terms of age, but they most often lived in the countryside, and every third member was obese. They were also the worst educated. They did physical or mixed work, and half of them worked shifts, including nights, which most probably had a negative impact on the quality of their sleep.

They assessed their material situation and health in the most negative way of all the groups, also in comparison with other people of their age. Almost two-thirds 


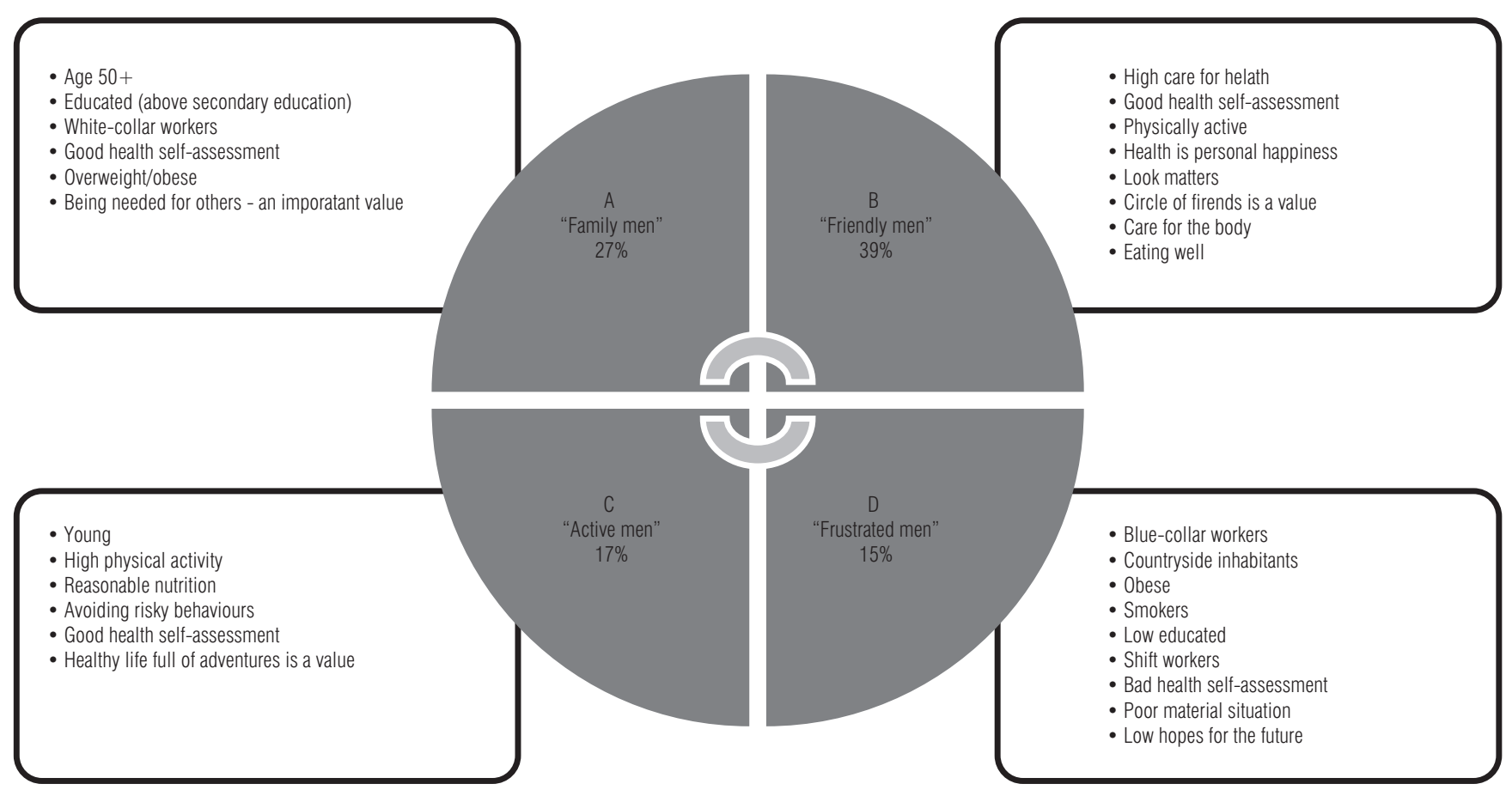

Figure 1. Breakdown of men into 4 groups based on cluster analysis with their most important characteristics (June 2017-June 2018, Poland)

declared that they did not care about these features, pointing out the lack of time, willingness and money as obstacles. If they cared for their health, it was only when they were ill - be it short-term or chronic disease. Only 1 in 5 declared taking up physical activity (the least of all groups), three-quarters smoked (the most of all groups), and they most frequently consumed alcohol (62\% drank beer at least once a week, and 16\% drank vodka at least once a week).

Men in this group were the least satisfied with their lives (19\% were not satisfied while in other groups this percentage did not exceed 9\%). Among personal values, they appreciated love, friendship and health less, while courage more than the others did. The individuals in this group had a low sense of self-control over their health, which was coupled with a lower trust in doctors, and they neither saw any connection between taking care of themselves and their well-being nor believed that the support of others could help in recovery. They perceived themselves as less sensitive, responsible, gentle, caring, competitive, success-oriented, powerful and confident, convincing, with a lower sense of humor, as well as less self-sufficient and even less friendly. They felt less hope for the future, joy and liveliness than all the other group members (Tables 2 and 3). The distinguished groups of men and their descriptive features are summarized in Figure 1.

\section{DISCUSSION}

The questionnaire survey conducted among 600 men confirms the general trends in men's approach to health, both in Poland and worldwide. The examined men, similar as in other reports $[2,4-6,13]$, rated their health and care for it highly; health occupied a high position in their hierarchy of values, yet their pro-health behaviors appeared insufficient. Most men took care of their health on an average level, arguing that this was mainly due to the lack of time. It was one of the most frequently mentioned barriers for men to adopt a healthy lifestyle, especially as regards physical activity and nutrition [14]. Detailed results related to care for one's health and its predictors among Polish men are presented in a paper titled "Positive health behaviors and their determinants among men active on the labor market in Poland" [7].

One of the most important results and conclusions of the conducted research is the fact that the care for men's health is determined mainly by the socio-economic status (including education and financial situation) and the type of work performed.

The socio-economic status is one of the most important factors determining the person's health status and health behaviors $[4,15,16]$, which has also been confirmed by independent research. The men surveyed clearly split into those with a high socio-economic status 
and those with a low status. The former were white-collar workers, had at least secondary education and declared that they were taking some actions in the field of healthy lifestyle - they claimed to eat rationally and exercise at least to the minimum extent as recommended by WHO [17], while the latter, on the contrary.

Most attention is attracted by the smallest group of men, called the "Frustrated". The men included in that group had a negative and pessimistic view of life; they assessed their health as bad and did not take care of it. They were men with a low socio-economic status, performing manual labor. They were people who did not notice the connection between caring for health and well-being; therefore; they constituted the most difficult group to motivate to change their lifestyle to a healthy one. Thus, it is essential to educate men, especially at their workplace where people with different educational backgrounds, health knowledge, awareness and needs group together. Investing in men's health through properly designed and delivered health education can bring multiple benefits, especially for men with the lowest socio-economic status, performing manual work, often working shifts (including nights), and thus exposed to numerous harmful factors, both within and outside the workplace [2].

A report by WHO [1] found that the focus in the male population today should be on healthy eating at work, at home and in all environments, reducing the consumption of alcohol, smoking and all other psychoactive substances, and also on mental health.

The factors conducive to health care, measured by the PHBS among the examined men, included: education (at least secondary), a good financial situation, positive opinions about work and life, and a high self-assessment of care for their health [7]. Demographic and socio-economic factors are among the main determinants of health, health behaviors and health inequalities; they determine the health of men rather than that of women [13]. Health behaviors are influenced by many factors, including housing, employment, education, cultural and social contexts. Moreover, a growing body of evidence suggests that factors affecting the concepts of masculinity and femininity, and the importance of gender roles in societies, have a huge impact on the health of men and women in the European region [13]. Men who support traditional (stereotypical) beliefs about masculinity engage in worse behaviors related to health and show a higher health risk than men who have a less traditional approach to gender roles [18]. The WHO reports $[1,13]$ highlighted the need to change the approach to women's and men's health, mainly because of the crucial role played by gender, and the associated social roles and stereotypes prevailing in this area.

Numerous Polish studies conducted since the 1990s have also shown that higher levels of education have resulted in healthier eating habits, more frequent physical activity, a reduction in the number of smokers and higher smoking cessation rates [19]. Further nationwide representative studies, conducted within the framework of programs concerning cardiovascular diseases (since 2002) [20,21], indicated, e.g., worse health parameters among those less educated (e.g., more frequent obesity and overweight), a lower level of knowledge of the possibilities of preventing hypertension or its complications, and less healthy diet. The results of the Social Diagnosis [22] conducted on a representative sample of Poles since 2000, cyclically every 2 years until now, have indicated that lower education is associated with a more frequent use of the health care system, as well as smoking and alcohol consumption.

As far as employees are concerned, similar trends are confirmed by research conducted cyclically since 1988 by the Institute of Occupational Medicine (IOM) in Łódź. Their results indicate that worse education is associated with lower physical activity, more frequent smoking and alcohol consumption, and worse diet $[23,24]$. In addition, such individuals are less health-conscious, less satisfied with their health, and less likely to plan changes in and care for health. A lower level of education is also more often correlated with the lack of interest in media coverage of information on how to avoid diseases or take better care of one's health, and a sense that such messages are difficult to understand [24]. This suggests that health education and health promotion programs (including at the workplace) should pay particular attention to this group of people.

Men, and in particular those with a low level of education and thus often performing hard physical work, are a group threatened by social exclusion in the sphere of health. As a consequence, they may have a worse position on the labor market, which indicates the need to extend the range of activities aimed at providing them with equal opportunities. One of the ways to achieve this goal may be proper health education and health promotion, as was mentioned above [25].

There is much evidence for the effectiveness of both health promotion at work in improving individual work ability by changing lifestyles to healthier ones [26], and the prevention of chronic diseases (e.g., diabetes and musculoskeletal disorders) [27-29]. 
Promoting the benefits of health, appearance/image, increased energy and physical fitness, as well as removing key barriers related to motivation, time shortage, financial constraints and improper nutritional habits can encourage men (especially young ones) to improve their lifestyles. Differences due to demographic and behavioral factors suggest that health promotion programs tailored to the different needs of men may need to be developed [30].

\section{CONCLUSIONS}

As a result of the research, it was confirmed that despite the fact that men have extensive theoretical knowledge about health, they still have a stereotypical approach to caring for health, largely determined by their socio-economic status, age, and type of work. Detailed results are presented in a paper by Hildt-Ciupińska and Pawłowska-Cyprysiak [7].

The surveyed men assessed their health highly and declared taking great care of it. They placed health high in their hierarchy of values and, as expected, they defined care for health as: following rational nutrition, undertaking physical activity, limiting alcohol consumption and not smoking, or effectively coping with stress. However, the discrepancy between the declarations and the actual health-oriented measures was disturbing.

Undoubtedly, there is a great need for actions aimed not only at constantly increasing knowledge and health awareness, but also promoting pro-health behaviors in the group of men, especially young, low-educated, and performing manual work, often including shifts. In the conducted research, they constituted the smallest group, referred to as the "Frustrated" (15\%), but it requires most attention. It also gives indications that this group should be covered by broader research in the future, in order to be able to plan a specific type of health education.

\section{REFERENCES}

1. World Health Organization [Internet]. Geneva: The Organization; 2018 [cited 2018 Oct 24]. The Health and Well-Being of Men in the WHO European Region: Better Health through a Gender Approach. Available from: http:// www.quotidianosanita.it/allegati/allegato1555823.pdf.

2. White A. The State of Men's Health in Europe [Internet]. Report. European Union; 2011 [cited 2018 Oct 24]. Avaliable from: https:/ec.europa.eu/health/sites/health/ files/state/docs/men_health_extended_en.pdf.
3. Ornish D, Scherwitz LW, Billings JH, Gould KL, Merritt TA, Sparler S, et al. Intensive lifestyle changes for reversal of coronary heart disease. JAMA. 1998;280(23):2001-7, https://doi.org/10.1001/jama.280.23.2001.

4. Wojtyniak B, Goryński P. The health situation of the Polish population and its conditions. Warsaw: National Institute of Public Health - National Institute of Hygiene; 2016.

5. Główny Urząd Statystyczny [Internet]. Warszawa: 2015 [cited 2018 Oct 24]. Health and health behavior of Polish citizens in the light of the European Health Survey Questionnaire (EHIS) in 2014. Available from: https:// stat.gov.pl/en/topics/health/health/health-status-of-population-in-poland-in-2014,4,1.html.

6. Cianciara D. Zdrowie - męska rzecz. Warsaw: Siemens; 2012.

7. Hildt-Ciupińska K, Pawłowska-Cyprysiak K. Positive Health Bahaviors and Their Determinants Among Men Active on the Labour Market in Poland. Am J Men Health. 2020:1-10, https://doi.org/10.1177\%2F15579883 19899236.

8. Woynarowska-Sołdan M, Węziak-Białowolska D. Psychometric analysis of the Positive Health Behaviour Scale for adults. Probl Hig Epidemiol. 2012;93(2):369-76.

9. Juczyński Z. [Measuring tools used in psychology and health promotion]. Warsaw: Laboratory of Psychological Test; 2001. Polish.

10. Tuomi K, Ilmarinnen J, Jahkola A, Katajarinne L, Tulkki A. Work Ability Index. Helsinki: Finnish Institute of Occupational Health; 1998.

11. Kuczyńska A. [Psychological gender assessment inventory. Handbook]. Warsaw: Laboratory of Psychological Tests, Polish Psychological Society; 2012. Polish.

12. Kristensen TS. Borg V. The Copenhagen Psychosocial Questionnaire-a tool for the assessment and improvement of the psychosocial work environment. Scand J Work Environ Health. 2005;31(6):438-49, https://doi.org/10. 5271/sjweh.948.

13. World Health Organization [Internet]. Geneva: The Organization; 2018 [cited 2018 Oct 24]. Strategy on the Health and Well-Being of Men in the WHO European Region. Available from: http://www.euro.who.int/_data/assets/pdf_file/0003/378165/68wd12e_MensHealth Strategy_180480.pdf?ua=1.

14. Ashton LM, Hutchesson MJ, Rollo ME. Motivators and Barriers to Engaging in Healthy Eating and Physical Activity: A Cross-Sectional Survey in Young Adult Men. Am J Men Health. 2017;11(2):330-43, https://doi.org/10. $1177 / 1557988316680936$.

15. World Health Organization [Internet]. Geneva: The Organization; 2018 [cited 2018 Oct 24]. Review of Social 
Determinants and the Health Divide in the WHOEuropean Region: Final Report. World Health Organization, 2018. Available from: http://www.euro.who.int/_data/assets/ pdf_file/0004/251878/Review-of-social-determinantsand-the-health-divide-in-the-WHO-European-RegionFINAL-REPORT.pdf.

16. Courtneay WH. Key determinants of the health and well-being of men and boys. Int J Men Health. 2003;(1): 1-30, https://doi.org/10.3149/jmh.0201.1.

17. World Health Organization [Internet]. Geneva: The Organization; 2010 [cited 2018 Oct 24]. Global Recommendations on Physical Activity for Health. Available from: https://www.who.int/dietphysicalactivity/global-PA-recs2010.pdf.

18. Hooker SP, Wilcox S, Burroughs EL, Rheaume CE, Courtneay W. The potential influence of masculine identity on health-improving behaviour in midlife and older African American men. J Mens Health. 2012;9(2):79-88, https://doi.org/10.1016/j.jomh.2012.02.001.

19. Ostrowska A, editor. Lifestyle and healt. Warszawa: IFiS PAN; 1999.

20. Piwońska A, Piotrowski W, Kozela M, Pająk A, Nadrowski P, Kozakiewicz K, et al. Cardiovascular Diseases Prevention in Poland: Results of WOBASZ and WOBASZ II Studies. Kardiol Pol. 2018;76:1534-41, https://doi.org/10. 5603/KP.a2018.0154.

21. Zdrojewski T, Rutkowski M, Bandosz P, Gaciong Z, Jedrzejczak T, Solnica B, et al. Prevalence and Control of Cardiovascular Risk Factors in Poland. Assumptions and Objectives of the NATPOL 2011 Survey. Kardiol Pol. 2013;71(4):381-92, https://doi.org/10.5603/KP.2013.0066.

22. Szkoła Główna Handlowa [Internet]. Szkoła; 2020 [cited 2018 Oct 24]. Czapiński J, Panek T. Social Diagnosis. Objective and Subjective Quality of Life in Poland 20002015. Available from: http://www.diagnoza.com/.

23. Gniazdowski A, editor. [Health behaviours of industrial workers outside the workplace. In: Health behaviours. Theoretical issues, attempt to characterise the health behaviours of the population of Poland]. Łódź: Instytut Medycyny Pracy; 1990. Polish.
24. Korzeniowska E. [Health awareness of professionally active people with a low level of education as a challenge for health education. In: Chrzanowska I, Jachimczak B, editors. The place of the Other in modern upbringing sciences. Practical challenges]. Łódź: Wydawnictwo Uniwersytetu Łódzkiego; 2008. Polish.

25. Korzeniowska E. [Workers with low level of education and their health - Polish example. In: Korzeniowska E, Puchalski K, editors. Workers with low level of education and their health - challenges for health education]. Łódź: Instytut Medycyny Pracy; 2010. Polish.

26. Oakman J, Neupane S, Proper KI, Kinsman N, Nygård CH. Workplace Interventions to Improve Work Ability: A systematic Review and Meta-Analysis of Their Effectiveness. Scand J Work Environ Health. 2018;44(2):134-46, https:// doi.org/10.5271/sjweh.3685.

27. Liu K, Daviglus ML, Loria CM, Colangelo LA, Spring B, Moller AC, et al. Healthy Lifestyle Through Young Adulthood and the Presence of Low Cardiovascular Disease Risk Profile in Middle Age: The Coronary Artery Risk Development in (Young) Adults (CARDIA) Study. Circulation. 2012;125(8):996-1004, https://doi.org/10. 1161/CIRCULATIONAHA.111.060681.

28. Brown SA, Garcia AA, Zuñiga JA, Kimberly AL, Lewis A. Effectiveness of Workplace Diabetes Prevention Programs: A Systematic Review of the Evidence. Patient Educ Couns. 2018;101(6):1036-50, https://doi.org/10.1016/j.pec.2018. 01.001 .

29. Van Eerd D, Munhall C, Irvin E, Rempel D, Brewer S, van der Beek AJ, et al. Effectiveness of Workplace Interventions in the Prevention of Upper Extremity Musculoskeletal Disorders and Symptoms: an Update of the Evidence. Occup Environ Med. 2016;73:62-70, https://doi.org/10.1136/oemed-2015-102992.

30. Ashton LM, Morgan PJ, Hutchesson MJ, Rollo ME, Young MD, Collins CE. A systematic review of SNAPO (Smoking, Nutrition, Alcohol, Physical activity and Obesity) randomized controlled trials in young adult men. Prev Med. 2015;81:221-31, https://doi.org/10.1016/ j.ypmed.2015.09.005.

This work is available in Open Access model and licensed under a Creative Commons Attribution-NonCommercial 3.0 Poland License - http://creativecommons.org/licenses/by-nc/3.0/pl/deed.en. 